\title{
Sexual Dimorphism in a Trophically Polymorphic Cichlid Fish?
}

\author{
Christopher Darrin Hulsey, ${ }^{1 *}$ Francisco J. García-De León, ${ }^{2}$ and Axel Meyer ${ }^{1}$ \\ ${ }^{1}$ Department of Biology, University of Konstanz, Konstanz 78457, Germany \\ ${ }^{2}$ Laboratorio De Genética Para La Conservación, Centro De Investigaciones \\ Biológicas Del Noroeste, Instituto Politécnico Nacional 195, La Paz, B.C.S. 23096, Mexico
}

\begin{abstract}
Sexual dimorphism in ecologically relevant traits is ubiquitous in animals. However, other types of intraspecific phenotypic divergence, such as trophic polymorphism, are less common. Because linkage to sex should often lead to balancing selection, understanding the association between sex and phenotypic divergence could help explain why particular species show high morphological variability. To determine if sexual dimorphism could be helping to maintain ecomorphological variation in a classic case of intraspecific trophic polymorphism, we examined the association between sex and morphological divergence in the cichlid Herichthys min ckleyi. Although $H$. minckleyi with enlarged molariform teeth on their pharyngeal jaws have been reported to more commonly be male, we did not find an association between sex and pharyngeal morphotype. Sex was associated with divergence in body size (as measured through standard length). But, sex was not associated with any of the other trophic traits examined. However, pharyngeal morphotype did show an association with gut length, gape, and tooth number. Sexual dimorphism is not playing a central role in enhancing trophic diversity within H. minckleyi. J. Morphol. 276:1448 1454, 2015. (C) 2015 Wiley Periodicals, Inc.
\end{abstract}

KEY WORDS: incipient speciation; functional morphology; modularity; pharyngeal jaw; sex-linkage

\section{INTRODUCTION}

The two sexes of many organisms are morphologically distinct (Darwin, 1871). For example, many stickleback (Gasterosteus aculeatus) populations have sexually dimorphic gill rakers, internal structures that are tightly tied to resource use in these fishes (Reimchen and Nosil, 2001). While less common, intraspecific divergence can also take the form of discreet ecomorphological phenotypes that are independent of sex (Smith, 1987; Meyer, 1989, 1990a, 1990b; Bolnick et al., 2003b; Lee et al., 2010). Although the advantages of maintaining two alternative sexual phenotypes within populations have been extensively explored, the factors maintaining other types of intraspecific polymorphism are often less clear (Meyer, 1993; Smith and Skúlason, 1996). Yet, because sexual phenotypes are often maintained due to frequency dependent processes that lead to a balance in the number of females and males within a population, associations with sex could provide a simple mechanism whereby extensive intraspecific variation is maintained (Slatkin, 1984; Parker, 2006). To determine if sexual dimorphism could play a role in the maintenance of ecomorphological variation in a fish species exhibiting a classic case of trophic polymorphism, we examined the association between sex and morphological divergence in the cichlid Herichthys minckleyi.

Sex could often be tightly linked with intraspecific differences in ecologically relevant traits and a large number of fishes exhibit this type of sexual dimorphism (Shine, 1989; Pyron, 1996; Kajiura et al., 2005; Schütz et al., 2006; Herler et al., 2010; Tsuboi et al., 2012; McGee and Wainwright, 2013; Tsuboi et al., 2015). For instance, divergence in male and female body size could lead indirectly to resource partitioning if, for example, the larger sex can consume larger prey (Shine, 1989; Katsikaros and Shine, 1997). Sex-specific energetic or nutritive requirements associated with producing offspring might also commonly lead to differential resource use (Belovsky, 1978; Slatkin, 1984), and in organisms with substantial parental care such as cichlids, differences in responsibilities to offspring might commonly lead to sex-biased trophic habits (Williamson, 1971). Furthermore, in adaptively diverging populations, lineage splitting could be more rapid when loci controlling ecologically relevant traits and those affecting mating preferences become linked (Wilson et al., 2000; Contract grant sponsor: CIBNOR (to F.J.G.-D.L.); Contract grant
sponsor: Deutsche Forschungsgemeinschaft and the University of
Konstanz (to A.M.).

*Correspondence to: C. Darrin Hulsey; Department of Biology, University of Konstanz, Konstanz 78457, Germany.

E-mail: darrin.hulsey@uni-konstanz.de 
A

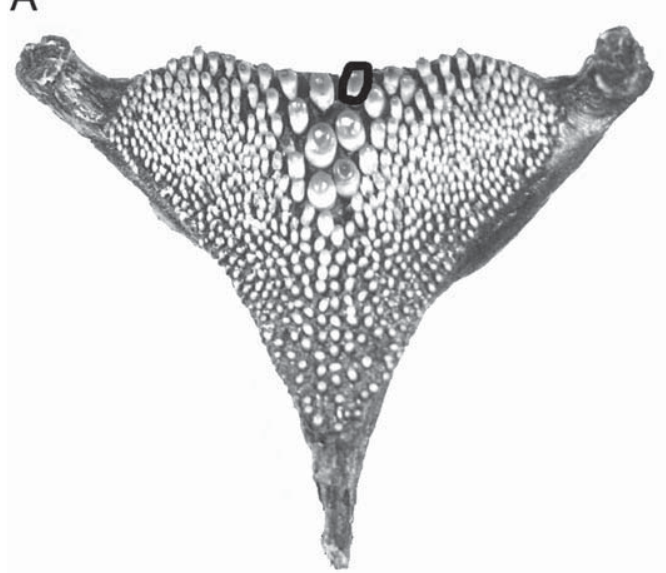

B

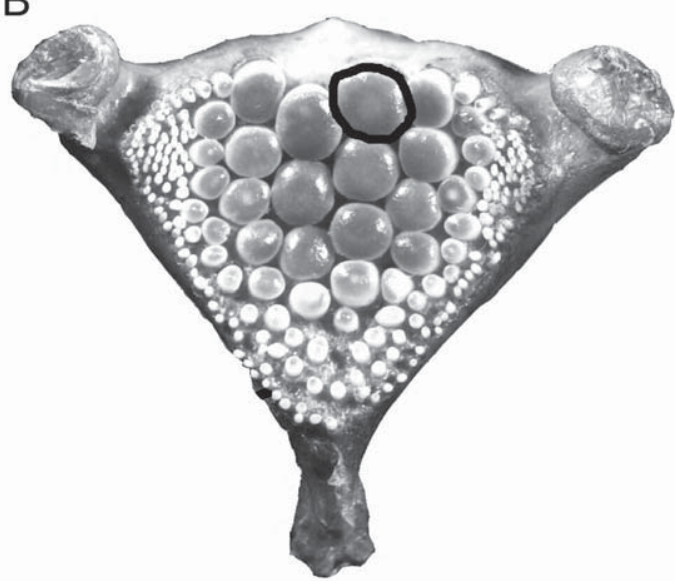

Fig. 1. The dorsal view of the papilliform (A) and molariform (B) lower pharyngeal jaw morphotypes in Herichthys minckleyi. The black circles highlight the size difference in a putatively homologous tooth. The pharyngeal jaws also differ in the number of teeth.

Gavrilets, 2003; Qvarnstrom and Bailey, 2008). For instance, in the rapidly evolving group of Lake Malawi cichlids, there exists a genetic association between sex and a number of traits that influence trophic divergence (Parnell et al., 2012). Sex could commonly play a role in the maintenance of highly variable phenotypes within populations.

However, there are multiple reasons that sex might not be associated with divergence in ecologically relevant traits. The ecological mechanisms driving processes such as adaptive speciation can widen the phenotypic distribution of a population and thus equalize the ecological effects of intraspecific competition (Roughgarden, 1972; Dieckmann and Doebeli, 1999). Because sexual dimorphism could often arise through competitive displacement (Slatkin, 1984), other types of adaptive intraspecific divergence could negate the ecological benefits of sexual dimorphism. Furthermore, if there is a link between intraspecific phenotypic divergence and a female's ability to choose morphologically similar mates, populations experiencing disruptive selection on ecologically relevant phenotypes could rapidly subdivide into distinct but nonsexually dimorphic species (Bolnick and Doebeli, 2003a; Barluenga et al., 2006). Therefore, it is interesting to document the role of sexual dimorphism in maintaining phenotypic divergence when a population is on the cusp of lineage divergence such as we might observe in a discrete intraspecific trophic polymorphism.

H. minckleyi is a cichlid fish that is phenotypically divergent in several aspects of its trophic morphology (Kornfield and Koehn, 1975; Sage and Selander, 1975; Trapani, 2003, 2004; Hulsey et al., 2005; Hulsey, 2006). Like most groups of fish, H. minckleyi has both oral and pharyngeal jaws. Generally, pharyngeal tooth size has been used to divide $H$. minckleyi into one of two pharyngeal morphotypes (Fig. 1). "Molariforms" have enlarged molar-like teeth and "papilliform" pharyngeal jaws exhibit only small pointed teeth (Kornfield and Taylor, 1983). The bimodal pharyngeal jaw variation in $H$. minckleyi is also associated with feeding differences (Swanson et al., 2003; Hulsey et al., 2005, 2006a, 2006b, 2008; Chaves-Campos et al., 2011). This type of discrete phenotypic difference might readily lead to the inference that the morphotypes should be diagnosed as two distinct evolutionary lineages with one specializing on shredding plants and another species that occupies a different feeding niche linked to crushing snails (Hulsey et al., 2006a). However, the two pharyngeal morphotypes have been observed to interbreed in the wild (Kornfield et al., 1982), consistently occur together in sympatry (Hulsey et al., 2008), and are indistinguishable at a large number of genetic loci (Kornfield and Koehn, 1975; Sage and Selander, 1975; Kornfield et al., 1982; Hulsey and García-De León, 2013).

The mechanisms maintaining trophic divergence in $H$. minckleyi are still unclear. However, the pharyngeal jaw morphology of $H$. minckleyi has been suggested to be sex-biased (Kornfield and Taylor, 1983). In the species description of $H$. minckleyi, it was suggested that the molariform morphotype was more commonly male implying a role for sexlinkage in maintaining this jaw polymorphism. However, in this previous analysis, only a subset of molariforms, those with relatively deep bodies, was reported to exhibit this pattern (Kornfield and Taylor, 1983) indicating there could be complex interactions between body depth, sex, and pharyngeal morphotype. Additionally, the sex-determining mechanism in $H$. minckleyi is currently unknown, and mechanisms ranging from sequential hermaphrodism, to social factors, to multilocus sex determiners could dictate sexual phenotype in this cichlid (Francis and Barlow, 1993; Carruth, 2000; Baroiller et al., 2009; Ser et al., 2010). Also, the 
size of the pharyngeal jaw teeth is not the only trait that is highly bimodal in $H$. minckleyi (Sage and Selander, 1975; Liem and Kaufman, 1984; Trapani, 2003, 2004; Hulsey et al., 2005; Hulsey, 2006a; Hulsey et al., 2008). Traits such as gut length and tooth number could be associated with pharyngeal tooth size and could also be sexually dimorphic. The oral jaws of $H$. minckleyi are also highly variable (Sage and Selander, 1975). Although oral jaw traits have been shown to be independent of the pharyngeal jaw diversity in $H$. minckleyi (Hulsey et al., 2005), phenotypes such as the size of the mouth or the amount of jaw protrusion could readily be associated with sex. Phenotypic associations with morphological differentiation of males and females could be an important factor in maintaining the substantial intraspecific variation in trophic morphology present in $H$. minckleyi.

To determine if sex is linked to variation in $H$. minckleyi trophic structure, we determined if males and females differed phenotypically within this polymorphic cichlid species. Using wildcaught $H$. minckleyi, we phenotyped the categorical variables sex and the presence of molariform pharyngeal teeth. Then, we quantified six traits that reflect trophic divergence in this cichlid. We first tested whether sex was associated with the bimodal pharyngeal morphotype in $H$. minckleyi. Then, we asked if the pharyngeal morphotype, sex, or the interaction between these two categorical variables were associated with variation in other trophically important $H$. minckleyi phenotypes. If sex does not maintain variation in these trophically relevant traits, the sexes should show no predictable differentiation in these traits. Alternatively, if males and females exhibit differences in these traits, this association could help to explain the maintenance of the exceptional trophic variability in $H$. minckleyi.

\section{METHODS}

We collected $150 \mathrm{H}$. minckleyi (Kornfield and Taylor, 1983) (83 molariform and 67 papilliform) individuals from the Cuatro Ciénegas valley in 2008. Individuals were phenotyped as either molariform or papilliform in the field. Pharyngeal morphotype assignments were based on the presence or absence of molari form teeth as determined using an otoscope placed into the mouth of the fish following methods outlined in Hulsey and García De León (2013). The two pharyngeal morphotypes were treated as a categorical factor for statistical analyses. The $H$. minckleyi individuals examined were chosen a priori to have a similar mean standard length (SL) of approximately $100 \mathrm{~mm}$ in order to reduce any effects of size on the comparisons of molariforms and papilliforms. The size range we used for analy ses spans almost the entire SL range of adults in this species since the maximum SL of $H$. minckleyi is reported to be $175 \mathrm{~mm}$ (Kullander, 2003). Importantly, there is no a priori rea son to expect a consistent size difference between the morpho types in the wild as both small as well as large papilliforms and molariforms are common in Cuatro Ciénegas populations (Hulsey et al., 2006).
In the field, we measured three additional traits on each fish. After individuals were anesthetized with MS 222, we used dial calipers to measure their SL as the distance from the upper jaw tip to the caudal peduncle. We also determined the amount each individual was able to maximally protrude its jaws using two measurements: 1) jaw closed and 2) jaw open. Jaw closed was measured as the distance from the anterior tip of the premaxilla to the most posterior point of the eye when the jaws were completely shut. Jaw open was determined as the distance from the anterior tip of the premaxilla to the most posterior point of the eye when the jaws were maximally extended. We then subtracted jaw closed from jaw open to determine maximum jaw protrusion. The gape, or diameter of the mouth opening from left to right, was measured using cali pers as the horizontal distance between the two coronoid proc esses of the articular bones when the oral jaws of the fishes were maximally extended. We made the assumption that the gape was relatively circular, and therefore did not measure dor soventral gape.

Once fish were preserved in formalin and transferred to ethanol in the laboratory, we measured body depth, lower pha ryngeal jaw tooth number, and gut length. First, we took a lat eral digital image of the right side of the body with a ruler in frame and imported it into the program ImageJ (Schneider et al., 2012). Body depth was determined as the distance between the anterior point of attachment of the pelvic fin and where the first dorsal spine inserted on the body. To determine the number of teeth on the lower pharyngeal jaws of the cichl ids, we dissected the fifth ceratobranchial from the fish. These bony elements were cleaned of all muscle and fascia and allowed to dry. Then, we took a digital image of the dorsal sur face of the jaws and imported it into ImageJ. The number of teeth on the lower pharyngeal jaw was then manually counted. Finally, we removed the entire digestive tract from the body cavity of the fish. Using dial calipers, we measured gut length as the length of the straightened digestive tract from the end where it attached on the posterior edge of the lower pharyngeal jaw to the anus of the fish.

Finally, because the sex of $H$. minckleyi is difficult to assign using external morphology, we determined the sex of specimens through dissection of the gonads using a light microscope. The gonads were removed from the body wall of the fish, and desig nations of sex were then based on previous studies of gonads in the closely related cichlid, Amphilophus citrinellus (Oldfield, 2011). In brief, females were identified based on the presence of oocytes. Males were determined based on the lack of oocytes as well as confirmation of the presence of spermatogenic cysts that are diagnostic for male reproductive structures.

To test for an association between sex and pharyngeal mor photype, we performed a chi square test on the deviation of the frequency of male and female molariforms and papilliforms from random. Then, to test if there was a difference in size between males and females, we performed a $t$ test on the SL of the two sexes. To account for minor differences in overall size in morphometric comparisons, we expressed all length variables as a percentage of SL. Because we chose $H$. minckleyi to ana lyze based on an a priori lack of difference in mean SL between molariforms and papilliforms, we did not analyze the differen ces in the size of molariforms or papilliforms or the interaction of SL with pharyngeal morphotype statistically. However, for the remaining five traits, we used general linear models imple mented in the R package lme4 (Bates et al., 2014) to determine whether the covariate of SL and the factors sex, pharyngeal morphotype, and the interaction between sex and pharyngeal morphotype explained variation in $H$. minckleyi trophic mor phology. We accounted for multiple comparisons statistically using the "holm" correction (Holm, 1979) and the p.adjust func tion in $\mathrm{R}$. This correction for multiple comparisons accounts for Type I error rates with sequentially modified $P$ values. Effec tively, raw $P$ values are ranked from largest to smallest (e.g., $P$ values: 1 st 0.7053 to 24 th 0.0001 ), multiplied by the rank number of comparisons that have equal or larger $P$ values (e.g., 
TABLE 1. Morphometrics and the linear model analyses using standard length (SL) as a covariate as well as the factors sex, mor photype, and an interaction between sex and morphotype

\begin{tabular}{|c|c|c|c|c|c|c|}
\hline & $t$ value & $P$ value & $\mathbf{M}_{+}$ & $\mathbf{M}_{\circlearrowleft}$ & $\mathrm{P}_{+}$ & $\mathrm{P}_{\hat{O}}^{\hat{\imath}}$ \\
\hline \multicolumn{7}{|l|}{ Gape } \\
\hline $\mathrm{SL}$ & 36.85 & $<0.0001$ & $14.3 \pm 1.0$ & $14.5 \pm 1.2$ & $14.8 \pm 1.2$ & $14.6 \pm 1.1$ \\
\hline Sex & 0.83 & 0.406 & & & & \\
\hline Morphotype & 2.64 & 0.009 & & & & \\
\hline Sex*morphotype & -1.81 & 0.072 & & & & \\
\hline \multicolumn{7}{|l|}{ Protrusion } \\
\hline SL & 18.05 & $<0.0001$ & $8.1 \pm 0.8$ & $8.2 \pm 1.2$ & $8.6 \pm 0.9$ & $7.9 \pm 0.9$ \\
\hline Sex & 0.35 & 0.725 & & & & \\
\hline Morphotype & 1.33 & 0.184 & & & & \\
\hline Sex*morphotype & -1.45 & 0.146 & & & & \\
\hline \multicolumn{7}{|l|}{ Gut length } \\
\hline SL & 10.03 & $<0.0001$ & $174.4 \pm 33.0$ & $183.5 \pm 37.2$ & $250.5 \pm 85.1$ & $213.6 \pm 67.4$ \\
\hline Sex & 0.56 & 0.577 & & & & \\
\hline Morphotype & 5.06 & $<0.0001$ & & & & \\
\hline Sex*morphotype & -1.80 & 0.073 & & & & \\
\hline \multicolumn{7}{|l|}{ Body depth } \\
\hline SL & 73.16 & $<0.0001$ & $45.2 \pm 2.5$ & $44.8 \pm 2.9$ & $43.6 \pm 3.1$ & $43.2 \pm 4.0$ \\
\hline Sex & -0.62 & 0.532 & & & & \\
\hline Morphotype & 1.34 & 0.183 & & & & \\
\hline Sex*morphotype & -1.45 & 0.147 & & & & \\
\hline \multicolumn{7}{|l|}{ Tooth number } \\
\hline SL & 1.90 & 0.059 & $220 \pm 76$ & $210 \pm 88$ & $423 \pm 67$ & $449 \pm 94$ \\
\hline Sex & -1.00 & 0.317 & & & & \\
\hline Morphotype & 10.00 & $<0.0001$ & & & & \\
\hline Sex*morphotype & 0.67 & 0.501 & & & & \\
\hline
\end{tabular}

The phenotypic values for body depth, jaw protrusion, gape, and gut length are all presented here as size corrected percentages of standard length (\% of SL). The values are divided into four categories representing the two pharyngeal morphotypes (M molariform and P papilliform) and sex (female $q$ and male $\left.\delta^{\top}\right)$. Phenotypic mean and plus/minus standard error are given for each category. The $t$ value from the linear models and $P$ values are reported. The association between sex and SL are not reported in this table because we a priori chose molariforms and papilliforms to have a similar average SL. Following correction for multiple statistical comparisons, all $P$ values below remained significant except the association of Morphotype with Gape (adjusted $P$ value $\quad 0.126$ ).

holm corrected 14 th smallest $P$ value $\quad 0.0090 \times 14 \quad 0.1261)$ and that value compared to $P \quad 0.05$. This sequential adjust ment results in less variables being considered significant as additional statistical comparisons are analyzed. Finally, because there were some outlier fish that had extremely long gut length, we removed the 10 longest gut length individuals and examined the sensitivity of our statistical analysis to these phe notypically extreme individuals.

\section{RESULTS}

Although we observed a trend in the expected direction, neither males (molariforms $=46$; papilliforms $=29$ ) nor females (molariforms $=37$; papilliforms $=38$ ) were significantly more likely to be molariforms $\left(X^{2}=2.18 ; P=0.139\right)$. The average SL of molariforms (102.3 mm) and of papilliforms $(99.4 \mathrm{~mm})$ were effectively equal in the 150 H. minckleyi that ranged in SL from 59.4 to $163.4 \mathrm{~mm}$. Females averaged 95.6-mm SL and males were on average approximately $10 \%$ longer at $106.3-\mathrm{mm}$ SL $(P=0.005$; adjusted $P$-val$\mathrm{ue}=0.075)$. Protrusion ranged from $5.8 \%$ to $10.3 \%$ of SL. We found sex was not related to gape, but contrary to previous analyses (Hulsey et al., $2006 \mathrm{~b}$ ), we recovered a significant association of gape with pharyngeal morphotype prior to adjustment for multiple comparisons $(P$-value $=0.009$; adjusted $P$-value $=0.126$ ). However, the difference observed was small as it is equivalent to a difference of approximately $0.3 \mathrm{~mm}$ in a $100-\mathrm{mm}$ fish. Protrusion showed no relationship to either sex or pharyngeal morphotype. Variation in body depth ranged from $28.2 \%$ to $52.2 \%$ of SL, but was unrelated to sex or pharyngeal morphotype. There was no influence of sex on the number of lower pharyngeal jaw teeth, but molariforms (215 \pm 83 S.E.) clearly tend $(P<0.001)$ to have only about half the number of teeth as papilliforms $(436 \pm 82$ S.E.). Gut length ranged from $69 \%$ to $460 \%$ of SL. On average, molariforms had a shorter gut length $(P<0.001)$ that was $179 \pm 34$ S.E.\% of SL, and with lengths of $235 \pm 79$ S.E.\% of SL, papilliforms showed almost twice the variability in their substantially longer guts (Table 1). This pattern held even when the individuals with the 10 longest guts, that were all papilliforms, were removed $(P=0.003)$.

\section{DISCUSSION}

Sex is associated with a limited amount of the morphological divergence in $H$. minckleyi. However, the male and female $H$. minckleyi SL did differ. We found that $H$. minckleyi males were on 
average almost $11 \%$ longer than females. This is similar to differences in body size observed in other closely related Heroine cichlids (Oldfield, 2011). Although males commonly tend to be larger than females in cichlids (Schütz and Taborsky, 2000; Schütz et al., 2006), the reasons for the body size differences between the sexes remain unclear. Sexual competition among males could readily favor larger body size (Schütz et al., 2006). Another reason for the size difference is that females tend to grow more slowly than males once they reach adulthood due to increased energetic costs in producing eggs during reproduction (Shine, 1989). Importantly, this size dimorphism in $H$. minckleyi could have clear ecological consequences since larger papilliform $H$. minckleyi could be better at assimilating nutrients from difficult to digest plant material and larger molariforms should be capable of crushing larger snails (Hulsey et al., 2005). Size dimorphism in H. minckelyi could be an ecologically critical trait that differentiates the sexes in this phenotypically variable cichlid fish.

Although molariforms were more frequently found to be males in our samples, we did not discover a statistically significant association between sex and pharyngeal jaw phenotype. Also, the previous suggestion that there is an interaction between body depth, pharyngeal jaw phenotype, and sex (Kornfield and Taylor, 1983) was not recovered here (Table 1). However, depending on the sex-determining mechanism in $H$. minckleyi, sex could still be playing a role in the polymorphism. For instance, if $H$. minckleyi was protogynous, a sequentially hermaphroditic species with females transforming into males, this could explain the average difference in size between the sexes. If there is a genetic basis to the trophic characters we have examined here, this plasticity in sex could also explain the lack of a relationship between sex and trophic phenotypes. Because our samples were chosen to be a particular size, size is associated with sex, and we do not have a clear understanding of what determines sex in $H$. minckleyi, some caution about the general lack of phenotypic association with sex is likely warranted.

Despite the lack of differences between the sexes, we did find gut length to be highly divergent between the two pharyngeal morphotypes as has been reported previously (Sage and Selander, 1975; Kornfield and Taylor, 1983). This association remained even when many papilliforms possessing gut lengths that were approximately four times their body length were excluded. Additionally, the number of teeth differed between the two morphotypes with papilliforms exhibiting almost twice the number of teeth as molariforms. Having twice the number of pharyngeal teeth and on average twice the gut length as molariforms likely benefits papilliforms when they are shredding and assimilating the hard to digest plant material they preferentially exploit (Hulsey et al., 2005, 2006a).

Because of the large number of traits that show divergence, the maintenance of the $H$. minckleyi pharyngeal polymorphism in the face of gene flow continues to be fascinating. In addition to the previously documented bimodality in lower pharyngeal jaw mass, levator posterior and levator externus IV muscle masses, the pharyngeal attachments of these muscles, lower pharyngeal jaw suturing, as well as gut length (Kornfield and Koehn, 1975; Sage and Selander, 1975; Trapani, 2003, 2004; Hulsey et al., 2005; Hulsey, 2006), our results suggest oral jaw gape and pharyngeal tooth numbers show an association with the $H$. minckleyi pharyngeal tooth polymorphism (Table 1). Undoubtedly, some of this association is maintained due to shared plastic responses to the hard snails and difficult to digest plant material that the two $H$. minckleyi pharyngeal morphotypes are specialized to exploit (Meyer, 1989, 1990a, 1990b, 1993; Hulsey et al., 2005, 2006a, 2006b). However, there is a genetic basis to the pharyngeal polymorphism as well (Trapani, 2003). Recently, it has become clear that the maintenance and parallel evolution of suites of adaptive traits in emerging model systems such as the stickleback are due in part to either plieotropy or colocalization of these phenotypes to the same chromosomes (Martin and Orgogozo, 2013; Miller et al., 2014). Although sex linkage is likely not responsible for the bimodality in the large suite of associated traits examined here, trait cosegregation within the genome or pleiotropy could play a role in the preservation of the trophic polymorphism in $H$. minckleyi.

Given the degree of craniofacial sexual dimorphism in other cichlids (Kajiura et al., 2005; Schütz et al., 2006; Herler et al., 2010; Parnell et al., 2012; Tsuboi et al., 2012, 2015) the lack of association of these phenotypes with sex in $H$. minckleyi is somewhat surprising. Future studies should determine if there is a genetic basis to the highly variable trophic phenotypes found in $H$. minckleyi as well as if they show any genetic linkage among themselves or to sex. However, the genomic basis of sex could be difficult to pinpoint because there are a number of sex-determining mechanisms in cichlids and sex itself could be plastic (Francis and Barlow, 1993; Baroiller et al., 2009; Ser et al., 2010). It is possible that H. minckleyi is a sequential hermaphrodite and females are capable of transforming into males at larger body sizes as is thought to occur in the South American cichlid Crenicara punctulata (Carruth, 2000). Cichlids also do not have clear sex chromosomes, and in African cichlids, it has been suggested that numerous unlinked loci contribute to sex determination (Baroiller et al., 2009; Ser et al., 2010). Nevertheless, detailed quantitative genetic analyses of the genomic basis of a number of traits 
in $H$. minckleyi could be used to not only test what sex-determining loci exist but if these loci appear to be physically unlinked to any chromosome containing loci that dictate differences in $H$. minckleyi trophic phenotypes (Parnell et al., 2012). Sex clearly does not play a substantial role in maintaining trophic variation in $H$. minckleyi. However, a complete understanding of why $H$. minckleyi exhibits such exceptional trophic variability will demand an improved understanding of all the mechanistic factors influencing not only sex and trophic variation but also the absence of an association between these two bimodal phenotypes maintained within a single polymorphic species.

\section{ACKNOWLEDGMENTS}

The authors thank Phillip Hollingsworth for field assistance. Katie Watson and Svenja Linder helped with phenotyping fish. The authors thank the Mexican government for providing us with permits to collect these fishes (Permiso de Pesca de Fomento $\mathrm{N}^{\circ} \mathrm{DAPA} / 2 / 130409 / 0961,230401-613$ 03 and DAN-01202 and DAN 02939). CDH and $\mathrm{AM}$ wrote the article. FJGDL and $\mathrm{CDH}$ collected the fish. All three authors helped collect the morphological data. The authors have no conflict of interest.

\section{LITERATURE CITED}

Barluenga M, Stolting KN, Salzburger W, Muschick M, Meyer A. 2006. Sympatric speciation in Nicaraguan crater lake cichlid fish. Nature 439:719 723.

Baroiller JF, D'Cotta H, Bezault E, Wessels S, Hoerstgen Schwark G. 2009. Tilapia sex determination: Where tempera ture and genetics meet. Comp Biochem Physiol A Mol Integr Physiol 153:30 38.

Bates D, Maechler M, Bolker B, Walker S. 2014. lme4: Linear mixed effects models using Eigen and S4. R package version 1.17 , http://CRAN.R project.org/package=lme4.

Belovsky GE. 1978. Diet optimization in a generalist herbivore: The moose. Theor Popul Biol 14:105 134.

Bolnick DI, Doebeli M. 2003a. Sexual dimorphism and adaptive speciation: Two sides of the same ecological coin. Evolution 57:2433 2449 .

Bolnick DI, Svanback R, Fordyce JA, Yang LH, Davis JM, Hulsey CD, Forister ML. 2003b. The ecology of individuals: incidence and implications of individual specialization. Am Nat 161:1 28.

Carruth LL. 2000. Freshwater cichlid Crenicara punctulata is a protogynous sequential hermaphrodite. Copeia 2000:71 82 .

Chaves Campos J, Johnson SG, Hulsey CD. 2011. Spatial geo graphic mosaic in an aquatic predator prey network. PLoS One 6:e22472.

Dieckmann U, Doebeli M. 1999. On the origin of species by sympatric speciation. Nature 400:354 357.

Darwin C. 1871. The Descent of Man and Selection in Relation to Sex. London: John Murray.

Francis RC, Barlow GW. 1993. Social control of primary sex dif ferentiation in the Midas cichlid. Proc Natl Acad Sci USA 90: 1067310675.

Gavrilets S. 2003. Models of speciation: What have we learned in 40 years? Evolution 57:2197 2215 .

Herler J, Kerschbaumer M, Mitteroecker P, Postl L, Sturmbauer C. 2010. Sexual dimorphism and population divergence in the Lake Tanganyika cichlid genus Tropheus. Front Zool 7:4.

Holm S. 1979. A simple sequential rejective multiple test proce dure. Scand J Stat 6:65 70 .

Hulsey CD. 2006. Function of a key morphological innovation: Fusion of the cichlid pharyngeal jaw. Proc R Soc Ser B 273: 669675

Hulsey CD, García De León FJ. 2013. Introgressive hybridiza tion in a trophically polymorphic cichlid. Ecol Evol 3:4536 4547.

Hulsey CD, Hendrickson DA, García De León FJ. 2005. Trophic morphology, feeding performance, and prey use in the poly morphic fish Herichthys minckleyi. Evol Ecol Res 7:303 324.

Hulsey CD, Marks J, Hendrickson DA, Williamson CA, Cohen AE, Stephens MJ. 2006a. Feeding specialization in Herich thys minckleyi: A trophically polymorphic fish. J Fish Biol 68: 112.

Hulsey CD, García De León FJ, Rodiles Hernández R. 2006b. Micro and macroevolutionary decoupling of cichlid jaws: A test of Liem's key innovation hypothesis. Evolution 60:2096 2109.

Hulsey CD, Roberts RJ, Lin ASP, Guldberg R, Streelman JT. 2008. Convergence in mechanically complex phenotype: Detecting structural adaptations for crushing in cichlid fish. Evolution 62:1587 1599.

Kajiura SM, Tyminski JP, Forni JB, Summers AP. 2005. The sexually dimorphic cephalofoil of Bonnethead Sharks, Sphyrna tiburo. Biol Bull 209:1 5.

Katsikaros K, Shine R. 1997. Sexual dimorphism in the tusked frog, Adelotus brevis (Anura: Myobatrachidae): The roles of natural and sexual selection. Biol J Linn Soc 60:39 51.

Kornfield IL, Koehn RK. 1975. Genetic variation and speciation in New World cichlids. Evolution 94:427 437.

Kornfield IL, Taylor JN. 1983. A new species of polymorphic fish, Cichlasoma minckleyi, from Cuatro Ciénegas, Mexico (Teleostei, Cichlidae). Proc Biol Soc Wash 96:253 269.

Kornfield IL, Smith DC, Gagnon PS, Taylor JN. 1982. The cichlid fish of Cuatro Ciénegas, Mexico: Direct evidence of conspecificity among distinct trophic morphs. Evolution 36: 658664

Kullander SO. 2003. Cichlidae (Cichlids). In: Reis RE, Kul lander SO, Ferraris CJJ, editors. Checklist of the Freshwater Fishes of South and Central America. Porto Alegre, Brasil: EDIPUCRS. pp 605654.

Lee HJ, Pittlik S, Jones JC, Salzburger W, Barluenga M, Meyer A. 2010. Genetic support for random mating between left and right mouth morphs in the dimorphic scale eating cichlid fish Perissodus microlepis from Lake Tanganyika. J Fish Biol 76:1940 1957.

Liem KF, Kaufman LS. 1984. Intraspecific macroevolution: Functional biology of the polymorphic cichlid species Cichla soma minckleyi. In: Echelle AA, Kornfield I, editors. Evolu tion of Fish Species Flocks. Orono, ME: University of Maine Press. pp 203215.

Martin A, Orgogozo V. 2013. The loci of repeated evolution: A catalog of genetic hotspots of phenotypic variation. Evolution 67:1235 1250 .

McGee MD, Wainwright PC. 2013. Sexual dimorphism in the feeding mechanism of threespine stickleback. J Exp Biol 216: 835840.

Meyer A. 1989. Costs and benefits of morphological specializa tion: Feeding performance in the trophically polymorphic Neotropical cichlid fish, Cichlasoma citrinellum. Oecologia 80: 431436

Meyer A. 1990a. Ecological and evolutionary aspects of the trophic polymorphism in Cichlasoma citrinellum (Pisces, Cichlidae). Biol J Linn Soc 39:279 299.

Meyer A. 1990b. Morphometrics and allometry in the trophi cally polymorphic cichlid fish, Cichlasoma citrinellum: Alter native adaptations and ontogenetic changes in shape. J Zool 221:237 260.

Meyer A. 1993. Trophic polymorphisms in cichlid fish: Do they represent intermediate steps during sympatric speciation and 
explain their rapid adaptive radiation? In: Schroder JH, Bauer J, Schartl M, editors. Trends in Ichthyology. Oxford, UK: Blackwell Publishing.

Miller CT, Glazer AM, Summers BR, Blackman BK, Norman AR, Shapiro MD, Cole BL, Peichel CL, Schluter D, Kingsley DM. 2014. Modular skeletal evolution in sticklebacks is con trolled by additive and clustered quantitative trait loci. Genetics 197:405 420.

Oldfield RG. 2011. Gonad development in Midas cichlids and the evolution of sex change in fishes. Evol Dev 13:352 360 .

Parker GA. 2006. The evolution of sexual size dimorphism in fish. J Fish Biol 41:1 20.

Parnell NF, Hulsey CD, Streelman JT. 2012. The genetic basis of a complex functional system. Evolution 66:3352 3366 .

Pyron M. 1996. Sexual size dimorphism and phylogeny in North American minnows. Biol J Linn Soc 57:327 341.

Qvarnstrom A, Bailey RI. 2008. Speciation through evolution of sex linked genes. Heredity 102:4 15 .

Reimchen TE, Nosil P. 2001. Ecological causes of sex biased parasitism in three spined stickleback (Gasterosteus aculea tus). Biol J Linn Soc 73:51 63

Roughgarden J. 1972. Evolution of niche width. Am Nat 106 683718.

Sage RD, Selander RK. 1975. Trophic radiation through poly morphism in cichlid fishes. Proc Natl Acad Sci USA 72:4669 4673.

Schneider CA, Rasband WS, Eliceiri K. 2012. NIH Image to ImageJ: 25 years of image analysis. Nat Method 9:671 675 .

Schutz D, Taborsky M. 2000. Giant males or dwarf females: What determines the extreme sexual size dimorphism in Lamprologus callipterus? J Fish Biol 57:1254 1265.

Schutz D, Parker GA, Taborsky M, Sato T. 2006. An optimality approach to male and female body sizes in an extremely size dimorphic cichlid fish. Evol Ecol Res 8:1 16
Ser JR, Roberts RB, Kocher TD. 2010. Multiple interacting loci control sex determination in lake Malawi cichlid fish. Evolu tion 64:486 501 .

Shine R. 1989. Ecological causes for the evolution of sexual dimorphism: A review of the evidence. Q Rev Biol 64:419 461.

Slatkin M. 1984. Ecological causes of sexual dimorphism. Evo lution 38:622 630 .

Smith TB. 1987. Bill size polymorphism and intraspecific niche utilization in an African finch. Nature 329:717 719.

Smith TB, Skúlason S. 1996. Evolutionary significance of resource polymorphisms in fishes, amphibians, and birds. Ann Rev Ecol Syst 27:111 133.

Swanson BO, Marks JC, Gibb AC, Hendrickson DA. 2003. Trophic polymorphism and behavioral differences decrease intra specific competition in a cichlid, Herichthys minckleyi. Ecology 84:1441 1446.

Trapani J. 2003. Morphological variability in the Cuatro Ciénegas cichlid, Cichlasoma minckleyi. J Fish Biol 62:276 298.

Trapani J. 2004. A morphometric analysis of polymorphism in the pharyngeal dentition of Cichlasoma minckleyi (Teleostei, Cichlidae). Arch Oral Biol 49:825 835

Tsuboi M, Gonzalez Voyer A, Hooglund J, Kolm N. 2012. Ecol ogy and mating competition influence sexual dimorphism in Tanganyikan cichlids. Evol Ecol 26:171 185.

Tsuboi M, Gonzalez Voyer A, Kolm N. 2015. Functional cou pling constrains craniofacial diversification in Lake Tangan yika cichlids. Biol Lett 11:20141053.

Williamson P. 1971. Feeding ecology of the red eyed vireo (Vireo olivaceus) and associated foliage gleaning birds. Ecol Monogr 41:129 152 .

Wilson AB, Noack Kuhnmann K, Meyer A. 2000. Incipient spe ciation in sympatric Nicaraguan crater lake cichlid fishes: Sexual selection versus ecological diversification. Proc R Soc Ser B 267:2133 2141. 